\title{
Experimental Study on Shear Strength Parameters of Soil in Borehole Wall under Slurry Supporting Construction
}

\author{
Yuntao Zhou ${ }^{1,2, a}$, Shengwei Shi ${ }^{1,2, b}$, Yong Zhang ${ }^{1,2, c}$, Qiang Cai ${ }^{1,2, d}$ \\ ${ }^{1}$ Technical Center for Geological Hazard Prevention and Control, CGS, Chengdu, Sichuan 611734, \\ China \\ 2Institute of Exploration Technology CAGS, Chengdu, Sichuan 611734, China \\ azhouyuntao_13@sina.com, b519903933@qq.com, c16536763@qq.com, d29431951@qq.com
}

Keywords: shear strength parameter; experiment; slurry supporting; soil in the borehole wall Abstract. Slurry supporting is an effective measure to avoid the borehole collapse in the process of boring construction. Based on the indoor slurry-supported models, this paper has analyzed change law of shear strength of borehole wall with time by using indoor direct shear test. The following conclusions has been obtained through experiment: 1 . with the progressive increase of exposure time of side wall soil to the mud, the water content is first increased quickly, then increased slowly; 2 . the internal friction angle of side wall soil is first decreased then increased, and tends to be decreased slowly with the passage of time; 3 . as the exposure time of soil in the borehole wall to the mud is longer, the cohesion force is smaller, and tends to be first decreased sharply at the earlier stage and then decreased slowly. In the process of slurry supporting construction, the special attention should be paid to the situation that internal friction angle of the soil in the borehole wall is rapidly reduced within a short period of time, and the construction period should be reduced as far as possible so as to avoid the phenomenon of borehole collapse caused by the reduction of cohesive force.

\section{Introduction}

The technology of slurry supporting is an effective measure that avoids the hole collapse of cast-in-place pile including drilling and borehole for the stabilization of underground diaphragm wall chase. The extensive use of such technology benefits from the cohesive action of the mud and soil in the side wall and the action of hydrostatic pressure of the mud; the action of hydrostatic pressure is fixed for different depth of the hole, while the soil in the side borehole wall is continuously changing over time, especially the shear strength of the soil in side wall is deteriorated, which causes irreversible disasters such as the destabilization of the underground diaphragm wall chase and hole collapse. Therefore, it has an instructive significance for the construction of borehole engineering to study on the change law of shear strength parameters of soil in side drilling wall over time during the period of mud construction.

Currently, there are a large number of researches on the hole wall stability theory and construction technique during the slurry supporting construction by many scholars, for example, in the soft soil area of Shanghai, the positive circulation of slurry supporting is applied, to some extent, to increase roughness of hole wall and expand the diameter of pile hole so as to improve the bearing capacity of piles (Qiang Wang et al.,2011); the equation of sliding trajectory for instability of large-diameter sewage hole wall and its calculation formula of security coefficient of slippage surface are established by using the slippery theory of classical soil mechanics (Zuocheng Wang et al., 2012); the overall process of grooving excavation of underground diaphragm wall and concrete pouring construction is simulated by applying the three-dimensional finite difference method which is deemed to be applicable to the analysis of construction process of underground diaphragm wall (Yongchun Ding et al., 2007); the mechanics principle of slurry supporting at the time of pore-forming through drilling is discussed (Runxing Liu, 2011); the measures improving the shape of slurry supporting are proposed on the basis of the physical properties (including thickness, grain composition, water content etc.) and compressibility, strength and mechanical properties of the slurry supporting of cast-in-situ bored pile (Bin Dai et al., 2003); the characters of slurry supporting in the 
aspects of thickness, strength, grain composition, compression, water content are discussed through indoor experiment (Xiaoyong $\mathrm{Li}$ et al., 2000); the instability mechanism of slurry-supported excavation is discussed from the aspects of soil arching effect, time effect, global stability and local stability by mean of analyzing the influence factor of stability of slurry-supported excavation (Guohui Lei et al., 2006); when analyzing the slurry-supported stability of underground diaphragm wall, its calculation shall be made by using the total stress indicators (Wei Xu et al., 2003); the slurry that is played in the stability of trench wall and in individual soil particles is researched (Shengcai Li et al., 1990); the wall protection mechanism of compound sodium based bentonite is explained (Yong Yang, 2010); the limit hole depth of slurry-supported deep drilling hole is increasing as the density of mud and internal friction angle of soil in borehole wall increase and is decreasing as the bore diameter increases (Fenqiang $\mathrm{Xu}$, et al., 2004); the mathematical analysis model of stability of bore wall is established and corresponding protection measures are proposed by analyzing the effects and functions of stabilized protection of slurry in the bore hole based on the construction of cast-in-situ bored pile of Chongyang Bridge (Xiaoqing Li, et al., 2007)However, no above-mentioned research has been involved in the research on the rule of variation of shear strength parameters with time.

In this paper, based on the indoor slurry-supported model proposed, the rule of change in shear strength parameters of soil in borehole wall is researched by way of direct shear test, and the influence of degradation of shear strength parameters on the phenomenon of borehole collapse is discussed; in consequence, the research achievements obtained can provide scientific basis for the safety construction of slurry protection.

\section{Test Method}

Test Principles. Based on the typical soil mechanics theory, the failure law of shear strength of soil is applicable to the Mohr-Coulomb Failure Criterion, namely:

$$
\tau_{f}=\sigma \tan \varphi+c
$$

Wherein, $\tau_{f}$ is the shear strength of soil $(\mathrm{kPa}) ; \sigma$ is the normal stress on the surface of failure $(\mathrm{kPa})$; $\varphi$ is the internal friction angle of soil $\left({ }^{\circ}\right)$; $c$ is the cohesive force of soil $(\mathrm{kPa})$.

Therefore, in this paper, the consolidated quick direct shear test applicable to the soil in borehole wall is selected to conduct the shear strength test.

\section{Soil Sample and Mud Preparation for Test}

In general, the slurry-supported soil is the coarse-grained soil or cohesive soil, and the cohesive soil is selected for preparation of mud as the dissociation of shear strength of coarse-grained soil is great and the regularity of shear strength is weak, with the same cohesive soil as the soil in the side wall. For example, Fig. 1 shows the slurry-supported indoor model, that is to say the two cutting rings (with the inner diameter of $61.8 \mathrm{~mm}$ and the height of $20 \mathrm{~mm}$ ) are respectively filled with the soil in the mud and the soil in the side wall, and the two filled cutting rings are attached together, then the soil particles and water in the mud will be diffused to affect the shear strength parameters of soil in the wall. Upon the placement for 0 5 days, through separating the soil in the mud and the soil in the side wall, the shear strength parameters of soil in the wall subject to various periods are tested respectively.

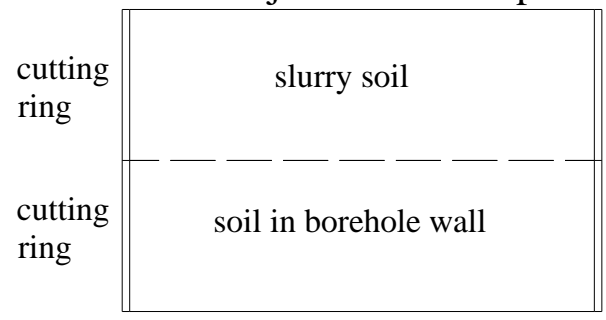

Fig.1 indoor model of slurry supporting

The soil samples for test are the cohesive soil (the diameter of particles $<0.075 \mathrm{~mm}$ ); the cohesive soil is weighted and added the water with the moisture content of $4 \%$, which should, upon 
the completion of intensive mixing, be put into the cutting rings (Fig. 2(a)); then the cutting rings are placed on the cutting rings which have been filled with soil in the wall, having them fixed with the adhesive tape (Fig. 2(b)); the cohesive soil is weighted and added the water with the moisture content of $20 \%$, which should, upon uniform mixing, be put into the cutting rings (Fig. 2(c)); and the completed soil samples of slurry-supported models are sealed (Fig.2(d)) and numbered respectively for test.
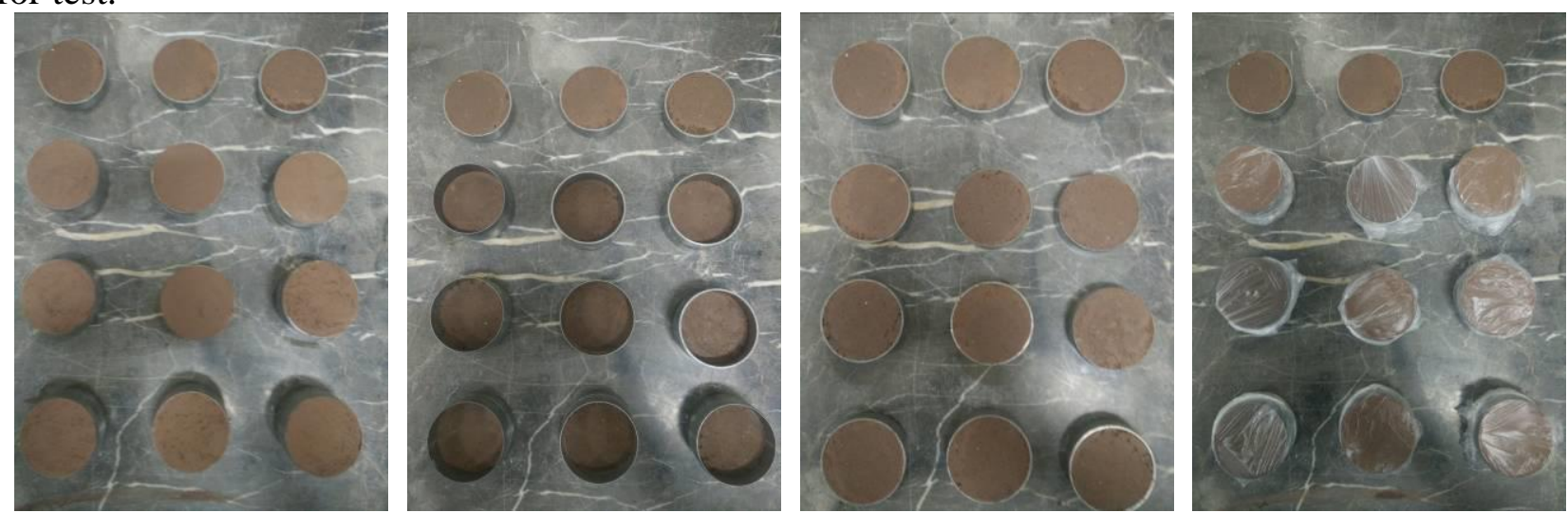

(a)the borehole wall soil filling(b)cutting ring placing(c)mud filling(d)seal by using plastic wrap

Fig. 2 manufacturing process of indoor model of slurry supporting

\section{Experiment Conditions}

In order to probe into the influence of shear strength at different periods, upon test deployment, select the soil in the mud with the viscosity of $20 \%$ and the soil in the wall with the initial water content of $10 \%$, and then put such two kinds of soil into the cutting rings and attach such cutting rings together, respectively experiencing $0 \mathrm{~d}, 0.25 \mathrm{~d}, 0.75 \mathrm{~d}, 1 \mathrm{~d}, 2 \mathrm{~d}, 3 \mathrm{~d}, 4 \mathrm{~d}$ and $5 \mathrm{~d}$; with 3 samples for each condition, the direct shear tests of them are conducted to test the shear strength parameters.

Table.1 experiment condition for slurry supporting

\begin{tabular}{ccccc}
\hline Condition & $\begin{array}{c}\text { Slurry } \\
\text { consistency(water } \\
\text { content)/(\%) }\end{array}$ & $\begin{array}{c}\text { Dration of } \\
\text { exposure/(d) }\end{array}$ & $\begin{array}{c}\text { Initial water content } \\
\text { of soil in borehole } \\
\text { wall/ }(\%)\end{array}$ & $\begin{array}{c}\text { Group } \\
\text { count }\end{array}$ \\
\hline 1 & & 0 & 10 & 3 \\
2 & & 0.25 & 10 & 3 \\
3 & 20 & 0.75 & 10 & 3 \\
4 & & 1 & 10 & 3 \\
5 & & 2 & 10 & 3 \\
6 & & 4 & 10 & 3 \\
7 & & 5 & 10 & 3 \\
8 & & & 10 & 3 \\
\hline
\end{tabular}

\section{Analysis of Test Results}

There are a total of 8 groups of conditions and 24 samples in the test, which obtains 24 groups of initial data. The shear strength parameters under different conditions are respectively obtained by processing 24 groups of data. Fig. 3 shows the relation curve between the shearing stress and shear displacement 2 days after the soil samples in the side wall are exposed to the mud; it can be seen that with the increase of overburden pressure, the shear stress is first sharply increased and then slowly increased and finally tends to be stable; the smaller the overburden pressure is, the faster the steady rate of shear stress curve is. 


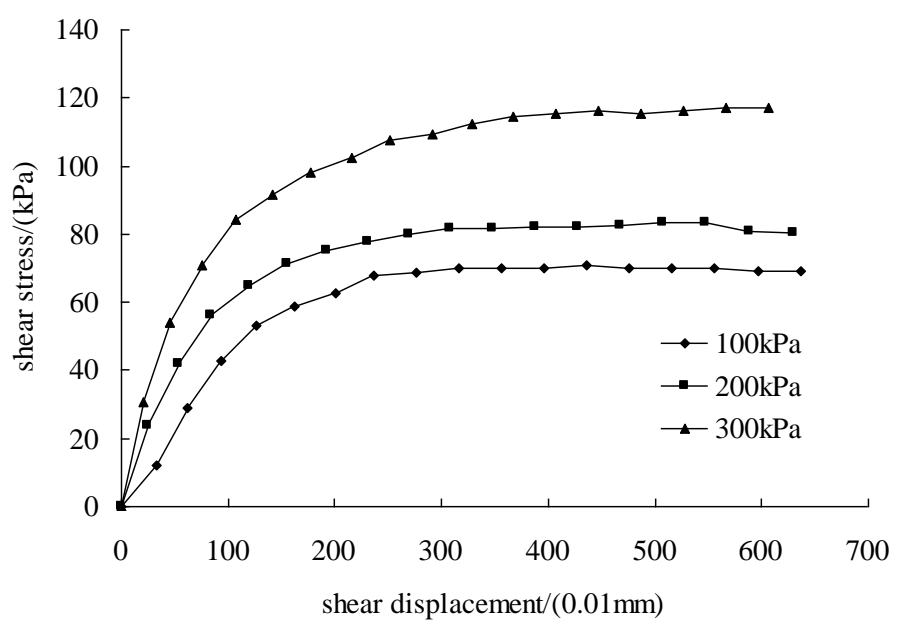

Fig.3 curve of shear stress and displacement for the borehole wall soil contacted in $2 \mathrm{~d}$ with mud

Fig.4 shows that with the progressive increase of duration of exposure between the soil in the side wall and the mud, the water content is first rapidly increased and later increased slowly. The initial moisture content of soil in the side wall is $10 \%$, and the initial moisture content of mud reaches $20 \%$; the moisture content of soil in the side wall is increased due to the constant diffusion of water with the exposure between soil in the side wall and the mud. In Fig.4, it also can be seen that at the time of $0.25 \mathrm{~d}$, the water content of soil in the side wall is rapidly increased from $10 \%$ to $11.5 \%$, and at the time of $0.25 \mathrm{~d}$ to $5 \mathrm{~d}$, the same is increased by $0.5 \%$, which demonstrates that the diffusion of water in the mud completes $75 \%$ within a very short time, and later, no significant phenomenon of water diffusion is found. Meanwhile, it is limited for the water in the mud to diffuse in the side wall soil, for example, in Fig.4, as regard to the side wall soil for $5 \mathrm{~d}$, the water content is only increased by $2 \%$.

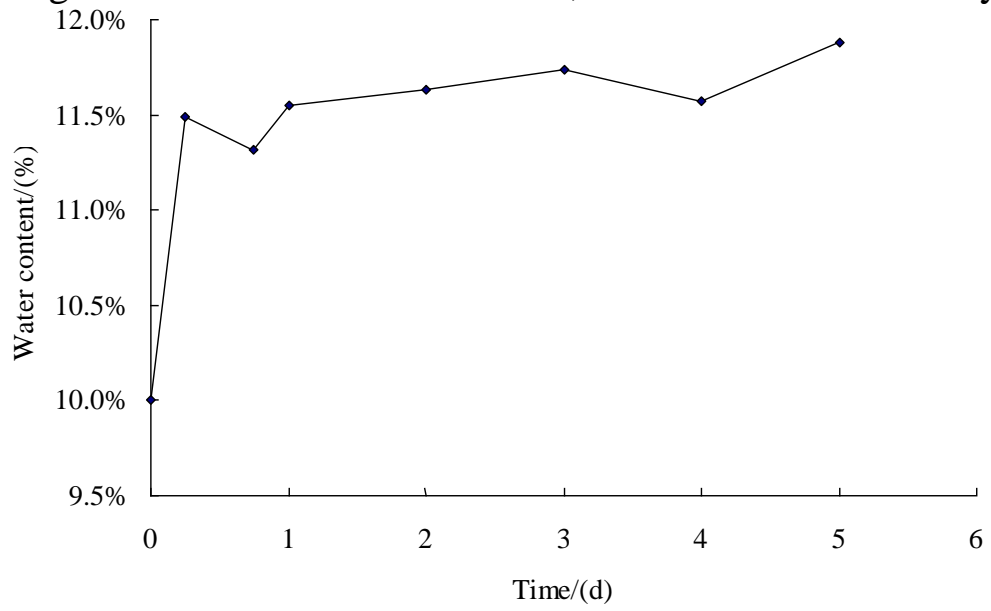

Fig.4 water content law with time history for the borehole wall soil

Fig.5 shows the curve of variation of internal friction angle of side wall soil with time, and it can be seen that the internal friction angle is first decreased and then increased with time, and then tends to be reduced slowly. Fig. 5 shows that the internal friction angle is minimum at the time of $0.25 \mathrm{~d}$, while Fig.4 shows that the water content is rapidly increased at such time, which is caused by that the rapid arrival of water leads to the water infiltration among the soil particles, with lubrication effects, and thus results in that the internal friction angle is rapidly reduced. With the further action of water, some soil particles or particle clusters are disintegrated to increase the exposure area, and as the significant reduction of lubrication effect of water, the internal friction angle is increased from $0.25 \mathrm{~d}$ to $1 \mathrm{~d}$. With the progressive increase of water content of side wall soil over time, the water content is constantly increased and the lubrication effect of water also is enhanced little by little, which reduces the action of friction among particles, and thus constantly reduces the internal friction angle. 


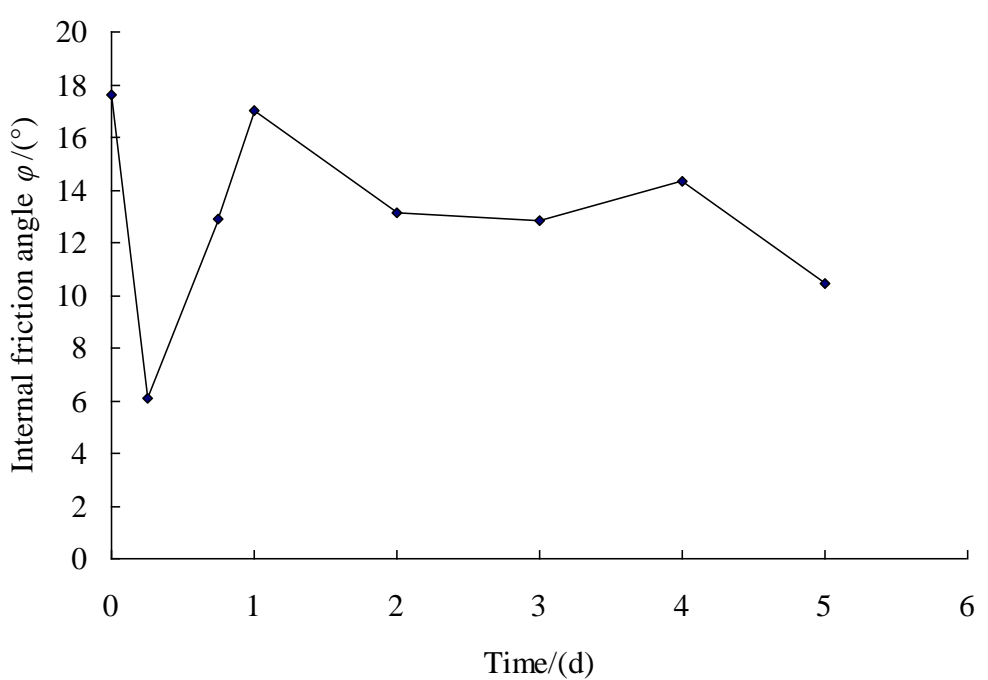

Fig.5 internal friction angle law with time history for the borehole wall soil

Fig. 6 shows that with the longer time of exposure of the side wall soil to the mud, the cohesive force is smaller, and tends to be sharply reduced at the earlier stage and then reduced slowly. The cohesive force is directly related to the water content; the higher the water content is, the lower the adhesion strength of soil is, and thus the reduction of cohesive force of soil is caused. With the increase of exposure time of the side wall soil, the water content is constantly reduced and thus the cohesive force is decreased continuously. In Fig.6, it can be seen that the curve of the cohesive force is sharply reduced at the earlier stage and then decreased slowly, which is also related to the increase rate of water content. It can be also found from Fig. 6 that with the exposure of side wall soil for $5 \mathrm{~d}$ to the mud, the cohesive force is reduced from $120 \mathrm{kPa}$ to $26 \mathrm{kPa}$, with the reduction rate reaching $78.3 \%$, which should be paid great attention during the construction, and the construction period shall be reduced to the greatest extent to avoid the phenomenon of borehole collapse arising from the reduction of cohesive force.

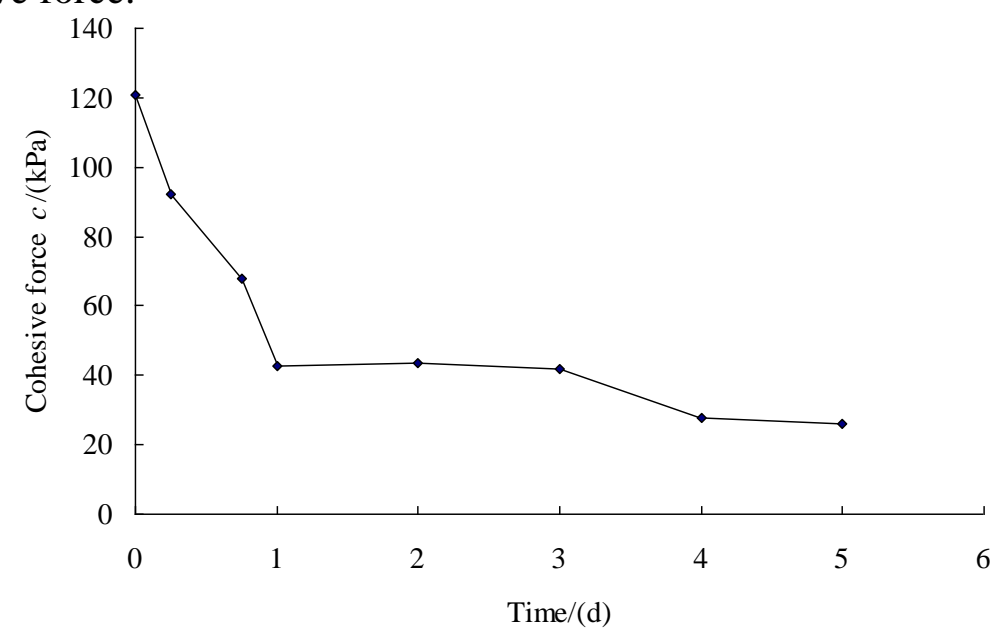

Fig.6 cohesion law with time history for the borehole wall soil

\section{Conclusions}

Based on the indoor slurry-supported models, the change law of shear strength parameters of soil in the borehole wall with time has been analyzed by using the indoor direct shear test. The conclusions can be obtained from the test as follows: 1 . with the progressive increase of exposure time of the side wall soil to the mud, the water content is rapidly increased and then slowly increased; 2 . the internal friction angle is first reduced and then increased with the passage of time, and finally tends to be reduced slowly; 3 . the longer the exposure time of side wall soil to the mud is, the smaller the cohesive force is, and the cohesive force tends to be sharply reduced at the earlier stage and then reduced slowly. During the slurry supporting construction, the special attention should be paid to the 
situation that the internal friction angle of soil in the borehole wall is rapidly reduced within the short time, and the construction period shall be reduced to the greatest extent to avoid the phenomenon of borehole collapse arising out of the reduction of cohesive force.

\section{Acknowledgements}

This work was financially supported by the Public Welfare Industry Special Projects of the Ministry of Land and Resources of China (201511051) and Project of China Geology Survey(DD20160278)

\section{References}

[1] Bin Dai. Study on engineering character of bored piles slurry-supported. Railway Construction Technology,(3):36-38(2003).(in Chinese)

[2] Fenqiang Xu ,Xu Wang . Research on stability of hole wall of deep bore with mud dado and limit deepness of bore hole[J]. Journal of Lanzhou Jiaotong University(Natural Sciences) ,23(4):9-12(2004).(in Chinese)

[3] Guohui Lei, Xuan Wang, Guogang Lei. Stability influencing factors and instability mechanism of slurry-supported excavations. Advances in Science and Technology of Water Resource,26(1):82-86(2006).(in Chinese)

[4] Qiang Wang, Chunfeng Zhao, Cheng Zhao, et al. Influence of normal and reverse mud circulations on hole diameter of cast-in-situ bored piles. Chinese Journal of Geotechnical Engineering,33(S2):205-208(2011).(in Chinese)

[5] Runxing Liu. Analysis of mechanical principle of slurry dado while bored piles being formed. Journal of Inner Mongolia University (Natural Science Edition),42(2):185-190(2011).(in Chinese)

[6] Shengcai Li, Wenjiao Deng. The study on the mechanism of dado with slurry. Journal of Fuxin Mining Institute,9(2):11-15(1990).(in Chinese)

[7] Wei Xu, Jianjun Zhou. Theoretical analysis study on stabilization of slurry wall. Building Construction,25(5):349-351(2003).(in Chinese)

[8] Xiaoyong Li, Kanghe Xie, Guoxi Zeng, et al. Test research on bored piles slurry-supported. Architecture Structure,30(5)21-23(2000).(in Chinese)

[9] Xiaoqing Li ,Xingzhou Hao ,Hongping Zhu, et al. Analysis on the stability of hole wall of large diameter bored pile[J]. Journal of Huazhong University of Science and Technology(Urban Science Edition) ,24(2):25-28(2007).(in Chinese)

[10] Yongchun Ding, Jianhua Wang, Yanbiao Chu, et al. Three-dimensional numerical analysis mechanical behavior of a constructing diaphragm wall panel. Rock and Soil Mechanics,28(8):1757-1761(2007).(in Chinese)

[11] Yong Yang. Stability -maintaining mechanism of compound sodium-based bentonite slurry and its application in practical engineering. Chinese journal of Underground Space and Engineering,6(4):838-844(2010).(in Chinese)

[12] Zuocheng Wang. Hole wall instability and mechanism of slurry protection about large diameter bilge well. Journal of Central South University(Science and Technology),43(12):4859-4864(2012).(in Chinese) 